\title{
PSYCHE
}

\begin{tabular}{lll} 
Vol. 7I & MARCH, I964 No. I \\
\hline
\end{tabular}

CHEMICAL RELEASERS OF SOCIAL BEHAVIOR. II. SOURCE AND SPECIFICITY OF THE ODOR TRAIL SUBSTANCES IN FOUR ATTINE GENERA. (HYMENOPTERA: FORMICIDAE) ${ }^{1}$

By Murray S. Blum², John C. Moser ${ }^{3}$, and A. D. Cordero ${ }^{4}$

The higher members of the tribe Attini characteristically lay persistent and extensive odor trails especially in many neotropical areas. Thus, in Acromyrmex and Atta, long columns of foraging workers are frequently present on the odor trails but in the less specialized attine genera, workers may forage either in files or singly. Weber (1958) has indicated that the workers in monomorphic genera forage singly, a behavioral characteristic which he offers as evidence for the primitive position of these attine genera.

Species in the genus Trachymyrmex appear to be intermediate, since they forage either singly or in columns. This, Weber concludes, indicates a transition to the well developed odor trails of the higher attines.

Since the Attini constitute a tribe of closely related genera which exhibit varying degrees of development of trail laying behavior, they are admirably suited for studies of odor trail laying.

The role of odor trail laying in the social biology of ants has been demonstrated clearly by Wilson ( I962) using an artificial trail technique. Previous investigations had demonstrated that the trail substances of the myrmicine Solenopsis saevissima (Fr. Smith) (Wilson, 1959) and several Dolichoderinae (Wilson and Pavan, 1959) originated as glandular secretions. Employing similar techniques, Moser and Blum (1963) demonstrated that the odor trail substance of one attine, Atta texana (Buckley), was a product of the poison glands.

\footnotetext{
${ }^{1}$ Based on research supported in part by U.S. National Science Foundation Grant No. G22074.

${ }^{2}$ Department of Entomology, Louisiana State University, Baton Rouge, Louisiana.

${ }^{3}$ U. S. D. A. Forest Service, Forest Insect Laboratory, Alexandria, Louisiana. Rica.

${ }^{4}$ Departmento de Entomologia, Universidad de Costa Rica, San Jose, Costa

Manuscript received by the editor May 14, 1963.
} 
It has now been possible to examine the glandular sources of the odor trail substances in four genera of the Attini and to determine their cross-specificities. The results of these studies are the subject of this paper.

\section{TEST SPECIES}

Based on morphology, behavior, and nest structure, Weber (1958) concludes that Cyphomyrmex rimosus (Spinola) is the most primitive of the attines. This species was selected as an ideal representative of the less specialized attine genera. Odor trail laying has not been noted in $C$. rimosus, which has been reported to forage singly. However, our own observations of the foraging behavior of workers from two colonies of this attine strongly indicate that this species lays odor trails. Both of the observed colonies were located in sandy soil at the base of trees (Pinus spp.) in Desoto National Forest near Gulfport, Mississippi. Each worker that emerged from the inconspicuous nest entrances moved slowly over the bark of the trees and made the same twists and turns as the workers that had preceded it. In two instances, pairs of workers emerged from the nest and moved with such complete synchrony that it seems very likely that odor trails were being followed.

The other attines examined were Trachymyrmex septentrionalis (McCook) ${ }^{5}$, Acromyrmex octospinosus (Reich) ${ }^{6}$, and Atta cephalotes (Linnaeus) ${ }^{6}$. In addition, odor trail species specificity studies were undertaken employing Atta texana .

\section{SOURCE OF TRAIL SUBSTANCES}

The sources of the odor trail substances were determined by using either a modification of the artificial trail technique of Wilson (r959) or the method of Moser and Blum ( I963). For all species examined, preliminary experiments indicated that the odor trail substances originated in the abdomen. Three organs in the abdomen, the hind gut, the paired poison glands and Dufour's gland, are known to secrete their contents into the external environment. These organs were dissected out of workers, washed in saline, and applied as smears on 75 $\mathrm{cm}$. sinusoidal trails drawn on pieces of $8,2 / 2$ × $\mathrm{II}$ " paper.

The trail-treated papers were placed either on glass platforms adjacent to laboratory colonies or in metal trays. Groups of Io ants from laboratory colonies were placed on the treated papers and a response was considered positive when a worker followed the trail to its

\footnotetext{
${ }^{5}$ Collected at Baton Rouge, Louisiana.

${ }^{6}$ Collected at Alajuela, Costa Rica.

${ }^{7}$ Collected at Forest Hill, Louisiana.

${ }^{8}$ Collected at Barro Colorado, Canal Zone.
} 
Table I. Response of attine workers to artificial trails prepared from three abdominal glands.

No. of Positive Responses

(Total Workers Responding in Parentheses)

\begin{tabular}{lcccc}
\multicolumn{1}{c}{ Species } & No. of Tests & Hind Gut & $\begin{array}{c}\text { Poison Gland } \\
\text { (Plus Vesicle) }\end{array}$ & Dufour's Gland \\
\hline $\begin{array}{l}\text { Cyphomyrmex rimosus } \\
\text { Trachymyrmex septentrionalis }\end{array}$ & 8 & $\mathrm{o}$ & $8(69)$ & $\mathrm{0}$ \\
Acromyrmex octospinosus & 10 & $\mathrm{I}(3)$ & $10(83)$ & 0 \\
Atta cephalotes & 10 & 0 & $10(78)$ & 0 \\
& 10 & $2(7)$ & $10(90)$ & 0 \\
\hline
\end{tabular}

end after crossing it during a three minute observation period. Although the major workers of Atta texana are too excitable to be employed in the artificial trail test (Moser and Blum, I963), the medium workers of Acromyrmex octospinosus and Atta cephalotes were found to be much more suitable than their minor workers for these tests. The results of these experiments are presented in table $\mathrm{I}$.

The poison glands are clearly the source of the odor trail substances in all four attine species. Ants frequently followed the artificial odor trails during the entire course of the observation period. When workers had run the entire length of the trail they would invariably overshoot and, often after milling around, they would encounter the artificial trail again and resume trail following.

\section{SPECIES-SPECIFICITY OF THE ODOR TRAIL SUBSTANCES}

Cross-species tests with artificial odor trails were made with the four attine species principally employing the circular trail technique of Moser and Blum (I963). Poison glands (and vesicle) were dissected out of freshly-killed or frozen workers and after rinsing in saline were crushed in $0.5-1.0 \mathrm{ml}$. of methylene chloride. Aliquots of 0.I-0.2 ml. of the methylene chloride solution of the poison gland contents were then applied with a pipette to a circle $6^{\prime \prime}$ in diameter and the solvent was allowed to evaporate. Subsequently, ro ants were introduced into the middle of the circle and the numbers of ants which, after encountering the circle, followed the circular trail for at least half its length were recorded.

As the data in table 2 demonstrate, the odor trail substances in the attine genera are not generic or species-specific. Although the artificial trails prepared from extracts of the poison glands of Atta and

\footnotetext{
${ }^{9}$ Ten workers per replication.
} 
Table 2. Numbers of workers responding to the poison gland secretion in the artificial test. Number of replications in parentheses. ${ }^{9}$

\begin{tabular}{|c|c|c|c|c|c|}
\hline & \multicolumn{5}{|c|}{ Test Species } \\
\hline & $\begin{array}{c}\text { Cyphomyrmex } \\
\text { rimosus }\end{array}$ & $\begin{array}{c}\text { Trachymyrmex } \\
\text { septentrionalis }\end{array}$ & $\begin{array}{c}\text { Acromyrmex } \\
\text { octospinosus }\end{array}$ & $\begin{array}{c}\text { Atta } \\
\text { cephalotes }\end{array}$ & $\begin{array}{l}\text { Atta } \\
\text { texana }\end{array}$ \\
\hline \multicolumn{6}{|l|}{ Source Species } \\
\hline Cyphomyrmex rimosus & $74(8)$ & $70(8)$ & - & - & $56(8)$ \\
\hline $\begin{array}{l}\text { Trachymyrmex } \\
\text { septentrionalis }\end{array}$ & $52(6)$ & $64(7)$ & $30(4)$ & $26(4)$ & $66(8)$ \\
\hline Acromyrmex octospinosus & - & $48(6)$ & $69(8)$ & $3 I(4)$ & $27(4)$ \\
\hline Atta cephalotes & 一 & $16(2)$ & $77(10)$ & $87(10)$ & $50(6)$ \\
\hline Atta texana & $63(8)$ & $54(6)$ & $34(4)$ & - & $33(4)$ \\
\hline
\end{tabular}

Acromyrmex sometimes produced a greater trail following response among all four genera than those obtained with Trachymyrmex and Cyphomyrmex extracts, no definite conclusions can be drawn from these results. The glands dissected out of Atta and Acromyrmex workers were generally larger than those obtained from the other two genera and conceivably they contained more odor trail substance. Eiven if all of the poison glands from all four genera were the same size, there would be no way of determining whether they all contained equal concentrations of the trail substances. Reliable quantitative experiments on the cross-generic activities of the attine odor trail substances must await isolation and identification of the pure pheromone (s).

The odor trail substances of the attines did not release trail following behavior in any non-attine species which were examined. Thus, no response was obtained with the odor trail laying ponerine Termitopone laevigata $\left(\mathrm{Fr}\right.$. Smith) ${ }^{8}$, the dorylines Eciton burchelli (Westwood $)^{7}$ and E. hamatum Forel. ${ }^{7}$, the myrmicines Crematogaster lineolata (Say) ${ }^{5}$, Monomorium minimum (Buckley) ${ }^{5}$, and Solenopsis saevissima (Fr. Smith) ${ }^{5}$ or the dolichoderines Conomyrma pyramica $(\text { Roger })^{5}$ and Iridomyrmex pruinosus $(\text { Roger })^{5}$.

\section{DISCUSSION AND CONCLUSIONS}

Based on external morphological features, the genera of the tribe Attini have the most easily recognized phylogenetic relationships of any of the myrmicine tribes (Creighton, 1950). Thus Trachymyrmex can be shown to grade into Atta and into the genus Cyphomyrmex through the transitional genus Mycetosoritis. The interrelationships of the attine genera are further supported by ethological evidence which largely parallels the morphological conclusions (Weber, 1958). 
Based on an examination of the glands associated with the sting in the attine genera Cyphomyrmex, Trachymyrmex, Acromyrmex, and $A t t a$, it appears that at least some internal morphological characters may be quite similar throughout the tribe. In Cyphomyrmex rimosus, the most primitive of the attines, (Weber, 1958), the paired free arms of the poison gland are rather blunt structures which are enclosed in a large bulbous vesicle. The vesicle rapidly narrows down to an extremely fine duct which is attached to a very reduced sting. Dufour's gland is inserted near the base of the sting and is considerably smaller than the poison glands. Notwithstanding differences in size, the form and relative proportions of the poison and Dufour's glands in Trachymyrmex, Acromyrmex, and Atta are virtually identical to those of Cyphomyrmex. Indeed the sting-associated glands of a minor worker of Atta cephalotes are a veritable carbon copy of those found in a Cyphomyrmex worker. It thus appears that the gross morphology of the poison apparatus of workers in the most primitive attine $C y$ phomyrmex, has undergone little change during the evolution of this tribe. The gross form of the glands associated with the reduced sting form a distinctive attine structure which may be an excellent diagnostic character for this tribe.

The lack of generic specificity of the odor trail substances of the four attines must be regarded as further evidence for the close relationship of the attine genera. In spite of the fact that Cyphomyrmex and Atta stand at the phylogenetic extremes of the tribe Attini, the odor trail substance of Cyphomyrmex is capable of releasing trail following behavior in Atta and vice versa. It is interesting to contrast the lack of generic specificity in the attine odor trail substances with the great specificity of the odor trail substances in the myrmicine genus Solenopsis. In transposition experiments with species of Solenopsis, Wilson (1962) demonstrated the odor trail substances of three members of this genus were highly species-specific. In addition, the Solenopsis trail substances produced no trail following in four other myrmicine genera. Similarly, the odor trail substances of the Attini do not produce any response in any of the myrmicine genera that we tested. One possible explanation that is consistent with the lack of specificity of the trail substances among the attines is that the odor trail chemicals are identical or closely related in the different genera. If this is correct, then the biogenetic pathway for the synthesis of the odor trail compound(s) in Cyphomyrmex has been utilized by the more highly developed attine genera with little modification. It is thus possible that the Attini are closely linked by the natural products chemistry of their poison glands. 
Since workers of the different attine genera follow each others' artificial trails in the laboratory, the question arises as to whether this occurs in the field. The tribe Attini is limited to the New World where most of the genera are sympatric. Weber (1958) has emphasized the fact that the attines are tolerant of one another as indicated by the fact that different genera forage beside one another, without any hostility. Furthermore, Weber notes that nests of genera such as Cyphomyrmex and Trachymyrmex are commonly found in the soil of the Atta mounds. These facts certainly emphasize the probability that under field conditions, the odor trails of different attine genera can frequently overlap. Indeed, strong trails of Atta cephalotes and Acromyrmex octospinosus crossed in at least two different places in a field that we observed at Alajuela, Costa Rica. In no instance were workers of either species observed to violate the other species' trail. When Acromyrmex workers were placed on the Atta trail, they invariably wandered off the trail almost at once and resumed trail following on their own trail when it was encountered. It does not seem unlikely that the persistent trails which attines follow over long periods contain secretions other than their odor trail substances which may render them more specific. Likely sources of trail additives are anal emissions which should present a considerable accumulation on a trail which is being utilized for extended periods. It is interesting to note that the odor trail of the formicine Lasius fulginosus (Latreille) is derived from an anal emission (Carthy, I95I). Whether attine odor trails maintain their specific identities among the tribal members because of supplemental secretions remains to be proven. However, in view of the non-specificity of the demonstrated odor trail substances among the Attini, it seems necessary to propose that additional chemical stimuli are present on the trails.

Nothing is known about the chemical nature of the attine odor trail substances. Preliminary examinations of the contents of the poison vesicles of the four attine genera indicate that all the secretions have similar physical properties. The vesicle contents are viscous, water-clear liquids which produce a strongly alkaline reaction with various indicator papers. When the poison vesicle is ruptured, its liquid contents immediately are converted into a semisolid mass. This latter property of the poison gland contents is certainly consistent with what is known about the general nature of the attine odor trail substances especially among the more highly developed genera. The persistent trails of Atta certainly reflect the presence of an odor trail substance(s) with a low vapor pressure. Assuming that the sting secreted odor trail substance similarly solidifies under field conditions, 
then the deposited compounds could be expected to be quite nonvolatile. That this is the case is indicated by the fact that artificial trails prepared from the poison glands (and vesicle) of Trachymyrmex were highly active when tested three weeks after their preparation. Furthermore, when poison glands of Atta cephalotes were crushed on microscope slides, the semisolidified secretion retained its original appearance for 28 days at room temperature (approximately $28^{\circ} \mathrm{C}$.) and released strong trail following behavior in Trachymyrmex when artificial trails were prepared from chloroform extracts.

\section{SUMMARY}

In Cyphomyrmex rimosus (Spinola), Trachymyrmex septentrionalis (McCook), Acromyrmex octospinosus (Reich) and Atta cephalotes (Linnaeus), four attine genera representing the broad phylogenetic development of the tribe Attini, odor trail substances originate in the poison glands. These substances, when cross genera tested, were found to be non-generic specific. This fact is interpreted as further evidence for the close relationship of the attine genera.

\section{REFERENCES}

CARThy, J. D.

1951. The orientation of two allied species of British ants. II. Odour trail laying and following in Acanthomyops (Lasius) fulginosus. Behaviour, $3: 304-318$.

Creighton, W. S.

1950. The ants of North America. Bull. Museum Comp. Zool. Harvard Coll, $104: 1-585,57$ plates.

Moser, J. C. AND M. S. Blum

1963. Source and potency of the trailmarking substance of the Texas leaf-cutting ant. Science $140: 1228$.

Weber, N. A.

1958. Evolution in fungous-growing ants. Proc. Intern. Congr. Entomol., 10th, Montreal, 1956, 2:459-473.

WiLson, E. O.

1959. Source and possible nature of the odor trail of the fire ant SoleWILSON, E。 O. nopsis saevissima (Fr. Smith) Science, $129: 643-644$.

1962. Chemical communication among workers of the fire ant Solenopsis saevissima (Fr. Smith). I. The organization of mass-foraging. Animal Behaviour, $10: 134-147$.

Wilson, E. O. and M. Pavan

1959. Source and specificity of chemical releasers of social behavior in the dolichoderine ants. Psyche, 66:70-76. 

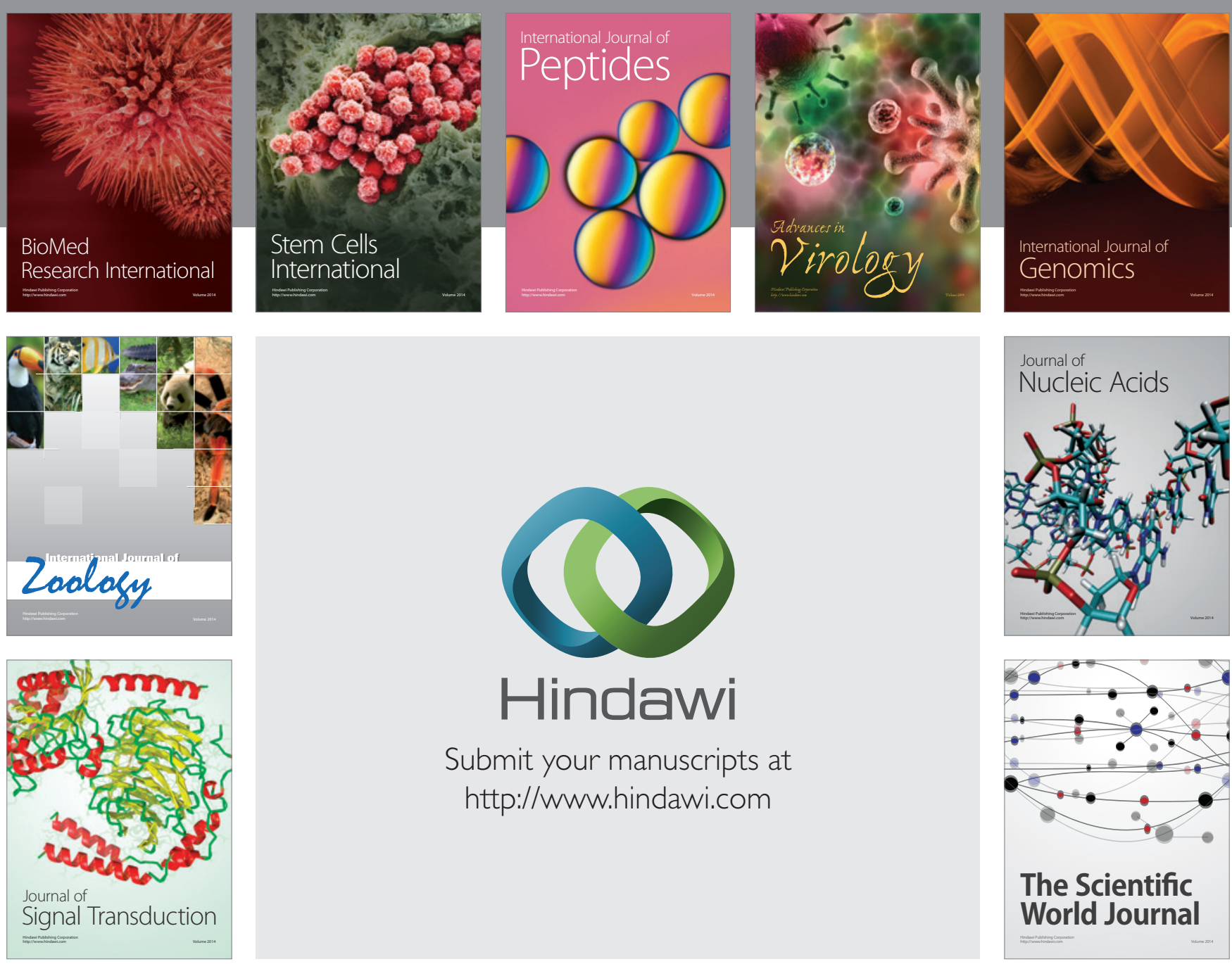

Submit your manuscripts at

http://www.hindawi.com
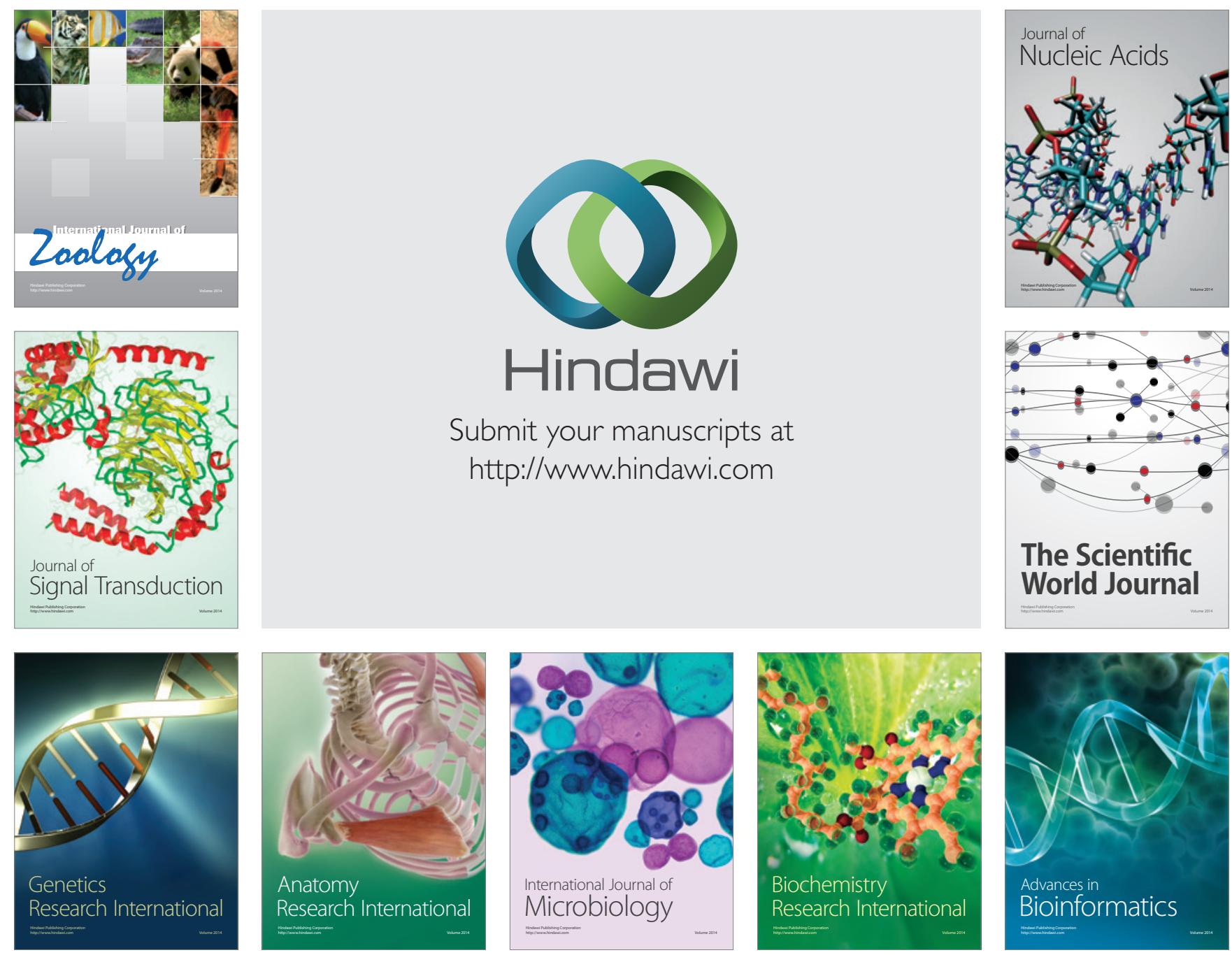

The Scientific World Journal
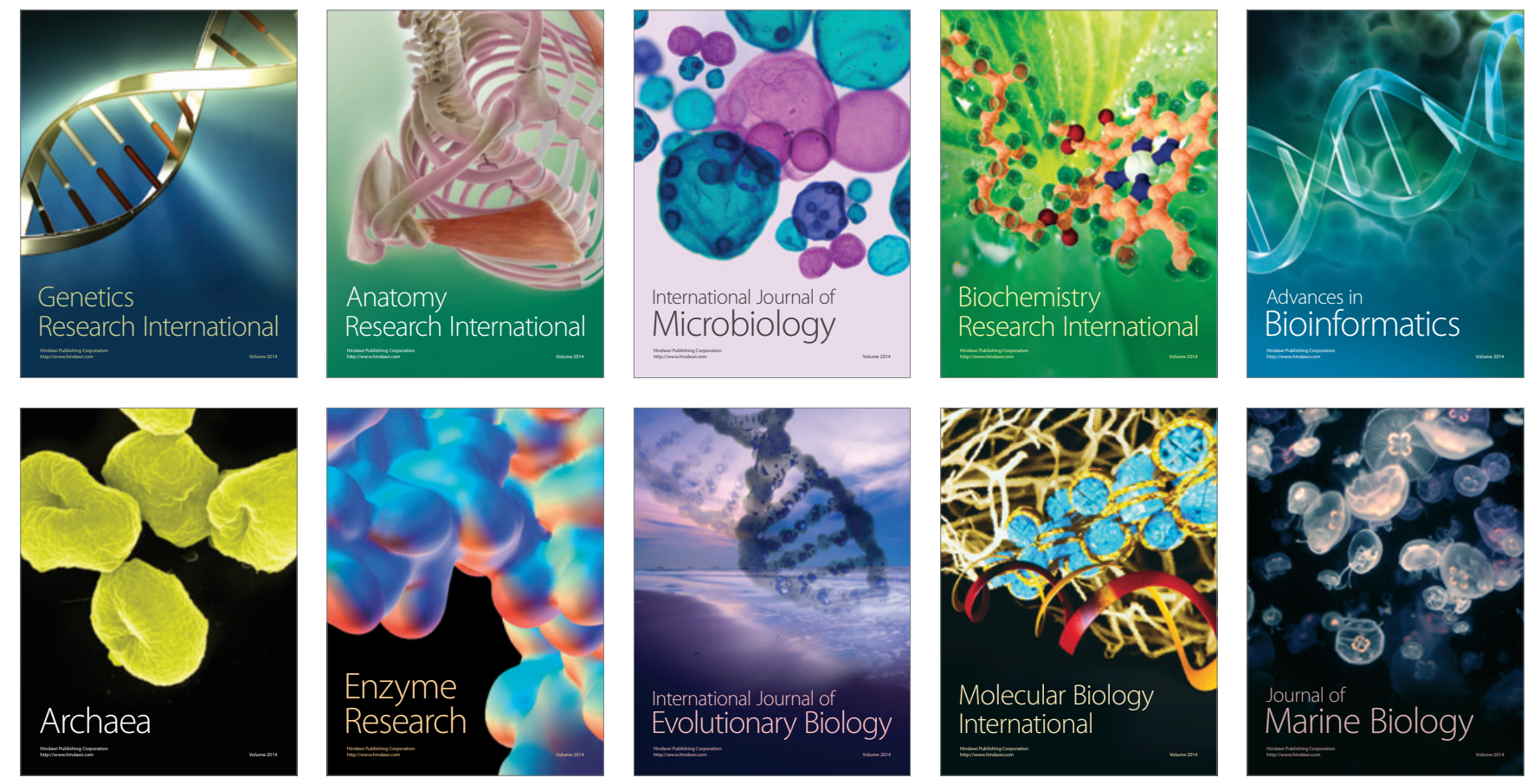